\title{
A pilot study on the removal of lactic acid and minerals from acid whey using membrane technology
}

Sahar Talebi ${ }^{\text {a }}$, Francisco Suarez ${ }^{\mathrm{b}}$, George Q. Chen ${ }^{\mathrm{a}}$, Xia Chen ${ }^{\mathrm{c}}$, Karren Bathurst ${ }^{\mathrm{b}}$, Sandra E. Kentish ${ }^{a^{*}}$

${ }^{a}$ The ARC Dairy Innovation Hub, Department of Chemical Engineering, University of Melbourne, Parkville, Victoria 3010, Australia

${ }^{\mathrm{b}}$ Bega Cheese Pty. Ltd., 23-45 Ridge Street, Bega, NSW 2550, Australia

c CAS Key Laboratory of Soft Matter Chemistry, Collaborative Innovation Center of Chemistry for Energy Materials, School of Chemistry and Materials Science, University of Science and Technology of China, Hefei, Anhui 230026, People's Republic of China

*Corresponding author, E-mail address: $\underline{\text { sandraek@ } @ \text { unimelb.edu.au }}$ 


\section{Abstract}

Acid whey presents a major disposal issue for the dairy industry due to its high lactic acid and mineral concentration. In this work, the feasibility of using membrane technology to treat acid whey to produce high quality whey powder was demonstrated at pilot scale. Three process combinations were tested, namely (1) ultrafiltration and electrodialysis, (2) ultrafiltration, nanofiltration and electrodialysis, and (3) ultrafiltration, dia-nanofiltration and electrodialysis. All three combinations were successful in reducing the levels of lactic acid and minerals in acid whey. However, the lowest ratio between lactic acid and lactose $(0.017 \mathrm{~g}$ lactic acid/ $\mathrm{g}$ of lactose) was obtained with the process utilizing dia-nanofiltration. The energy required for electrodialysis of ultrafiltration permeate and dia-nanofiltration retentate was comparable (7.5 and $7.8 \mathrm{kWh} /$ tonne of feed, respectively). However, the dia-nanofiltration retentate was at least 3.5 times more concentrated than the ultrafiltration permeate, thus reducing the annual energy consumption and capital investment of the electrodialysis unit. The product of the nanofiltration and electrodialysis process was successfully dried to produce a powder with an ash and moisture content of $4 \%$ and $2.5 \%$, respectively.

Keywords:

Acid whey, acid whey powder, lactic acid, membrane technology, electrodialysis 


\section{Introduction}

Acid whey, the by-product of cream cheese and yogurt manufacturing, presents a major disposal issue for the dairy industry. Unlike sweet whey, which is produced during rennet coagulation, acid whey is challenging to dry to powder due to the presence of lactic acid (LA) and high levels of calcium. ${ }^{1}$ The lactic acid imparts a sour taste to the final product and also lowers the glass transition temperature of the lactose, which can result in a sticky powder that renders spray drying impossible. ${ }^{1}$ Knipschildt \& Andersen ${ }^{2}$ showed that it was possible to increase the glass transition temperature of acid whey from $\sim 70^{\circ} \mathrm{C}$ to $95^{\circ} \mathrm{C}$, by decreasing the mass ratio of lactic acid to lactose from $0.2 \mathrm{~g} \mathrm{LA} / \mathrm{g}$ lactose to $0.04 \mathrm{~g}$ LA/g lactose. Currently, acid whey is concentrated and used as cattle feed, however this practice is not sustainable as the demand for cream cheese and yogurt is increasing, meaning that this stream can only be diverted to waste. As a result, producing whey powder from acid whey does not only add value to dairy operations by capturing the nutrients present in acid whey (i.e. protein and lactose), it will also provide a more sustainable approach to manage the increasing volumes of acid whey.

Both pressure and electrically driven membrane technologies are widely used by the dairy industry due to their ability to fractionate milk and dairy products. In pressure driven membrane processes, a pressure difference is applied to separate high molecular weight components into the retentate and low molecular weight components into the permeate stream. As an example, ultrafiltration (UF) is used to separate milk into proteins and lactose. ${ }^{3}$ In addition to separation by size, the separation mechanism in nanofiltration (NF) is also related to electrical charge. For example, NF membranes are able to achieve a greater removal of monovalent anions while retaining divalent anions due to the greater repulsion between the divalent anions and the negatively charged membrane. ${ }^{4} \mathrm{NF}$ membranes have proven successful for several dairy applications and are widely used in the treatment and concentration of sweet whey to produce whey powder. ${ }^{5}$ The removal of ions from the NF retentate can be further increased by utilizing 
dia-nanofiltration (Dia-NF), where water is added to the feed stream to flush more ions through to the permeate.

In electrically driven membrane processes, such as electrodialysis (ED), an electrical current is used to separate charged ions from uncharged molecules such as lactose and large charged molecules such as whey proteins. ${ }^{6}$ The process uses two different types of ion-exchange membranes (IEMs), known as cation exchange membranes (CEM) and anion exchange membranes (AEM). These membranes are arranged alternatively in the ED unit to prevent free migration of ions throughout the process. Arranging the membranes in such a manner creates the three main processing streams, namely: (1) the diluate stream that is demineralized and deacidified; (2) the concentrate stream that accumulates the ions lost by the diluate stream; and (3) the electrolyte stream that carries the electrical current through the electrolyte compartments and protects the electrodes.

Several researchers have proposed the use of membrane technology for acid whey treatment. For example, NF has been investigated at laboratory and pilot scale for separating LA and minerals from acid whey before drying. Chandrapala and Chen et al. ${ }^{7}$ found that at the natural $\mathrm{pH}$ of acid whey (4.2-4.5), only $30 \%$ of lactate was removed from the acid whey when NF was used. Similar results were observed by Bédas et al. ${ }^{8}$, who used a semi-industrial scale NF unit to remove $30 \%$ lactic acid and $46-60 \%$ of the monovalent ions from acid whey. The authors claimed that the dryability of acid whey increased after treatment. Chandrapala, et al. ${ }^{9}$ were unable to improve the lactic acid removal when using dia-nanofiltration (diafiltration factor of 1.5). Chen et al. ${ }^{10}$ used ED with two cell pairs and a membrane area of $72 \mathrm{~cm}^{2}$ to treat acid whey permeate. ED is usually terminated at $70 \%$ demineralization of the diluate stream to avoid high energy $\operatorname{costs}^{5}$ and in the work by Chen et al. ${ }^{10}, 50 \%$ of the lactic acid had been removed from the feed solution at this demineralization level. Talebi et al. ${ }^{11}$ observed fouling of the 
membranes during ED of sweet and acid whey and noted that while mineral deposits could readily be removed during cleaning, the protein deposits were not as easily avoided.

In this work, we combine NF and ED to achieve a greater level of lactic acid removal. UF is also used upstream to remove protein from the feed solution which might otherwise foul the downstream NF and ED processes. Kelly and Kelly ${ }^{12}$ briefly discuss the possibility of combining NF and ED for acid whey treatment, but do not describe any experimental work. Markel et al. ${ }^{13}$ processed nanofiltered acid whey through ED to obtain $70 \%$ and $90 \%$ demineralized solutions that were used in a bipolar-electrodialysis process for the purpose of adjusting the $\mathrm{pH}$ of the acid whey. In the work presented here, three different process combinations were examined (see Figure 1), namely (1) UF+ ED; (2) UF+ NF+ ED; and (3) UF+ Dia-NF+ ED. The experiments were performed in a pilot scale setting. This ensured that outcomes were close to that of a full-scale operation since the acid whey, cleaning chemicals and water supply were taken directly from the full scale dairy operations. Further, full size spiral would modules were used for the UF and NF operations. 
(a)

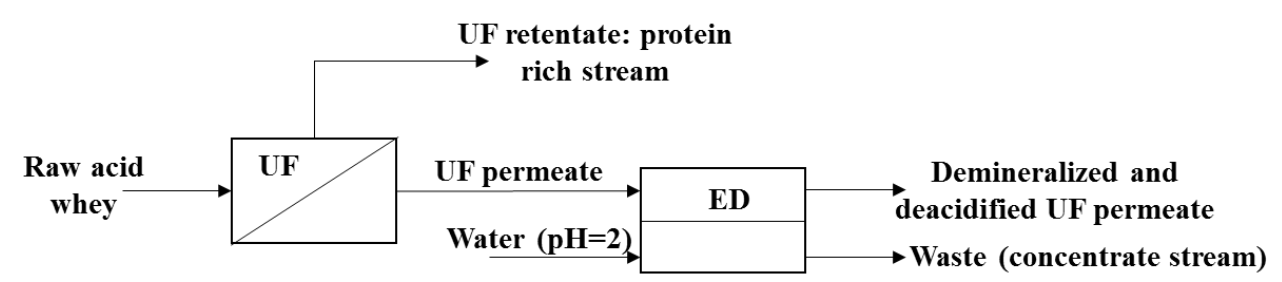

(b)

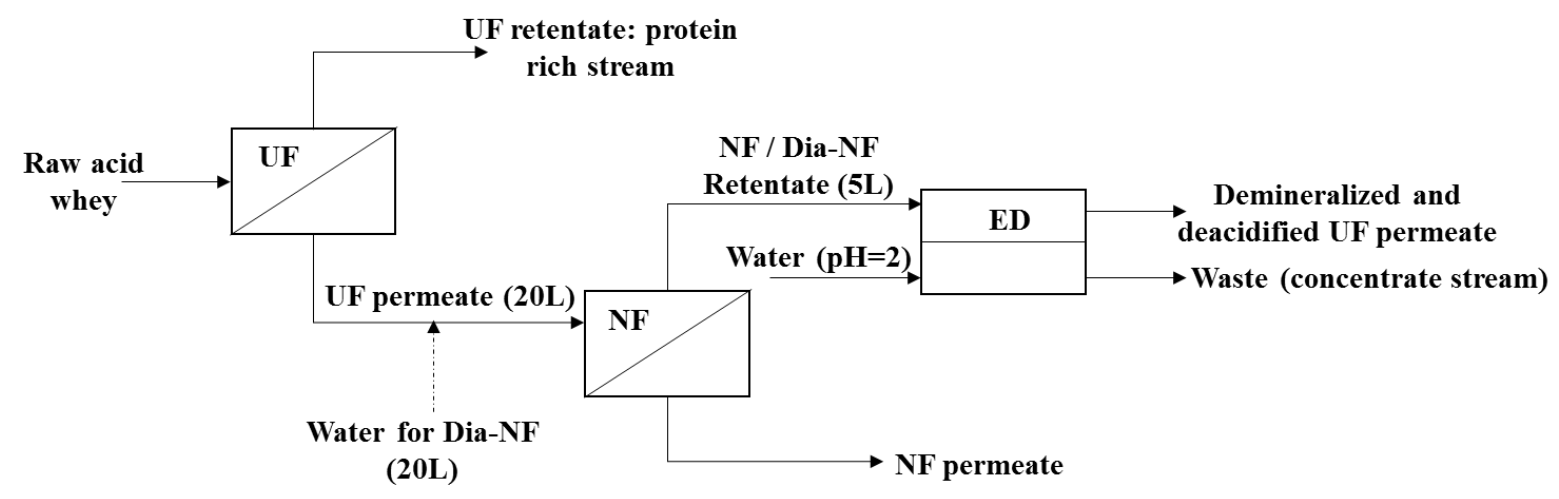

Figure 1. Proposed process flow diagrams for: (a) ultrafiltration and electrodialysis, and (b) ultrafiltration, nanofiltration or dia-nanofiltration and electrodialysis. UF= ultrafiltration, $\mathrm{NF}=$ nanofiltration, $\mathrm{Dia}-\mathrm{NF}=$ dia-nanofiltration, and $\mathrm{ED}=$ electrodialysis.

\section{Methods and Materials}

\section{Materials}

Fresh raw acid whey (Table 1) was obtained from Tatura Milk Industries Pty. Ltd. (Victoria, Australia). Spiral wound polyethersulfone UF membranes with a molecular weight cut-off of $10 \mathrm{kDa}$ and membrane area of $14 \mathrm{~m}^{2}$ were used for the UF process. The NF and Dia-NF processes were performed using a thin-film composite NF spiral wound membrane, with a total area of $14 \mathrm{~m}^{2}$, a molecular weight cut-off of 150-300 Da for uncharged molecules and a

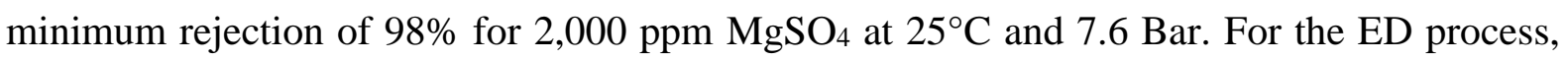
cation exchange membranes (Neosepta CMB) and anion exchange membranes (Neosepta AHA) were purchased from Astom Co., Ltd. (Tokyo, Japan). These membranes have a wide $\mathrm{pH}$ tolerance and thermal stability. Information on the IEM characteristics can be found 
elsewhere. ${ }^{10}$ An electrolyte solution of $20 \mathrm{~g} / \mathrm{L}$ sodium sulphate $\left(\mathrm{Na}_{2} \mathrm{SO}_{4} ;>99 \%\right.$; Thermo Fisher Scientific Australia Pty. Ltd., Australia) was prepared using purified water $(>8.6 \mathrm{M} \Omega \mathrm{cm}$; Merck Millipore KGaA, Germany), while mains supply tap water was used as the concentrate stream. The $\mathrm{pH}$ adjustment of the concentrate was performed using appropriate amounts of hydrochloric acid (36\% HCl; Thermo Fisher Scientific Australia Pty. Ltd., Australia), while the conductivity was adjusted using tap water. For all three processes, an alkaline cleaning step was performed using an industrial cleaning agent (P3-Ultrasil 69, Ecolab, Australia). The cleaning solution was prepared by adding appropriate amounts of the cleaning agent to tap water to achieve a $\mathrm{pH}$ of $10.5 \pm 0.5$.

\section{Ultrafiltration and nanofiltration pilot scale unit}

The UF and NF pilot plant, model R, was purchased from GEA, Australia. The pilot plant can operate up to 40 bar feed pressure. The feed solution was fed to the recirculation loop through a 60 L balance tank using a Hydra Cell pump type DG10 (Wanner Engineering, Australia). The UF and NF experiments were carried out at room temperature in a mode where the permeate was removed continuously while the retentate was redirected back to the feed tank. A double pipe heat exchanger supplied with cooling water was used to maintain the temperature. The feed pressure was maintained at 6 bar for UF, while the pressure was increased to 20 bar for NF. These values were selected based on the pressure ranges recommended by the pilot plant manufacturer. The total recirculation flowrate was set at $15,000 \mathrm{~L} / \mathrm{hr}$ to ensure steady performance of the centrifugal pump (type WHP +30/80, SPX Flow Technology, Poland) as the maximum capacity of this pump was $20,000 \mathrm{~L} / \mathrm{hr}$.

The raw acid whey was initially processed using UF membranes to generate a protein rich stream as retentate of around fivefold concentration and a lactose stream as permeate (Table 1 and Figure 1). The UF permeate was further processed through the NF membranes to produce 
a lactose rich stream (14-16\% TS) as retentate (Table 1). The UF permeate stream was also diafiltered using the NF membranes. A diafiltration factor of 1 was used, indicating that for every $100 \mathrm{~L}$ of UF permeate, $100 \mathrm{~L}$ of water was used. The diafiltration water was added once the UF permeate was processed through the NF unit to $15 \%$ total solids. Due to the limited capacity of the feed tank, the diafiltration water was added gradually to avoid overflow. The permeate stream was removed continuously while the retentate stream was recycled back to the feed tank. The process was terminated when the total solids again reached $15 \%$.

Table 1. The composition of raw acid whey and the three different types of solutions fed to the ED unit.

\begin{tabular}{|c|c|c|c|c|c|}
\hline Component & Unit & $\begin{array}{l}\text { Raw acid } \\
\text { whey }\end{array}$ & UF permeate & $\begin{array}{l}\text { NF retentate } \\
(\mathrm{CF}=3.5-4)^{\mathrm{a}}\end{array}$ & $\begin{array}{l}\text { Dia-NF } \\
\text { retentate } \\
(\mathrm{CF}=3.5-4)^{\mathrm{a}}\end{array}$ \\
\hline $\mathrm{pH}$ & - & $4.8 \pm 0.2$ & $4.4 \pm 0.2$ & $4.5 \pm 0.1$ & $4.3 \pm 0.2$ \\
\hline Conductivity & $\mathrm{mS} / \mathrm{cm}$ & $7.2 \pm 0.2$ & $6.9 \pm 0.2$ & $8.7 \pm 0.4$ & $5.0 \pm 0.1$ \\
\hline Total Solids ${ }^{b}$ & $\%(\mathrm{~m} / \mathrm{v})$ & $5.5 \pm 0.1$ & $4.0 \pm 0.3$ & $15 \pm 1$ & $15 \pm 1$ \\
\hline Total Protein ${ }^{\mathrm{b}}$ & $\%(\mathrm{~m} / \mathrm{v})$ & $0.46 \pm 0.05$ & $0.17 \pm 0.01$ & $0.38 \pm 0.02$ & $0.27 \pm 0.02$ \\
\hline $\mathrm{Ash}^{\mathrm{b}}$ & $\%(\mathrm{~m} / \mathrm{v})$ & $0.7 \pm 0.06$ & $0.55 \pm 0.07$ & $1.4 \pm 0.05$ & $1.1 \pm 0.05$ \\
\hline $\mathrm{Fat}^{\mathrm{b}}$ & $\%(\mathrm{~m} / \mathrm{v})$ & $0.11 \pm 0.01$ & Undetectable & Undetectable & Undetectable \\
\hline K & $\mathrm{mg} / 100 \mathrm{~mL}$ & $109 \pm 6$ & $104 \pm 7$ & $130 \pm 16$ & $11 \pm 2$ \\
\hline $\mathrm{Na}$ & $\mathrm{mg} / 100 \mathrm{~mL}$ & $43 \pm 8$ & $43 \pm 2$ & $52 \pm 9$ & $20 \pm 2$ \\
\hline $\mathrm{Ca}$ & $\mathrm{mg} / 100 \mathrm{~mL}$ & $114 \pm 5$ & $107 \pm 7$ & $400 \pm 39$ & $413 \pm 2$ \\
\hline $\mathrm{Mg}$ & $\mathrm{mg} / 100 \mathrm{~mL}$ & $12 \pm 0.5$ & $11 \pm 0.6$ & $41 \pm 5$ & $52 \pm 1$ \\
\hline $\mathrm{P}$ & $\mathrm{mg} / 100 \mathrm{~mL}$ & $63 \pm 2$ & $59 \pm 4$ & $198 \pm 13$ & $196 \pm 3$ \\
\hline $\mathrm{Cl}$ & $\mathrm{mg} / 100 \mathrm{~mL}$ & $80 \pm 8$ & $75 \pm 2$ & $108 \pm 8$ & $30 \pm 2$ \\
\hline Lactate & $\mathrm{g} / \mathrm{L}$ & $6 \pm 0.6$ & $5.7 \pm 0.3$ & $12 \pm 0.6$ & $6 \pm 0.5$ \\
\hline Lactose & $\mathrm{g} / \mathrm{L}$ & $44 \pm 2$ & $35 \pm 2$ & $132 \pm 9$ & $150 \pm 3$ \\
\hline
\end{tabular}

\footnotetext{
${ }^{a} \mathrm{CF}=$ concentration factor. ${ }^{\mathrm{b}}$ Measured in the laboratory of Tatura Milk Industries Pty. Ltd.
} 


\section{Electrodialysis pilot scale unit}

The ED experiments were conducted using an FT-TS40 module manufactured by FuMA-Tech GmbH (Bietigheim-Bissingen, Germany). Titanium-iridium coated plasma and stainless steel was used as the anode and the cathode, respectively. Starting with a CMB, a total of ten membrane cell pairs (10 CMB and 10 AHA) were installed between the two electrodes with alternating spacers to form the diluate and concentrate compartments. An eleventh CMB was used in front of the electrode compartment to prevent anion migration towards the electrodes. More information on the arrangement of the IEMs can be found elsewhere. ${ }^{14}$ The effective area per ion exchange membrane was $100 \mathrm{~cm}^{2}$. The pilot plant rig was fitted with three centrifugal pumps (MD 70 RZM, IWAKI Europe GmbH, Germany) and three cylindrical polyethylene tanks of 6L each (See Figure 2). A direct current power supply (Voltage regulator Type 3257.3, Statron Geratetechnik GmbH, Germany) was used to generate the potential difference across the membrane cell pairs. The output voltage ranged between $0-72 \mathrm{~V}$ while the current ranged between 0-20 A.

The ED experiments were conducted in a constant voltage mode of operation with the voltage set at $24 \mathrm{~V}$. The selected voltage was calculated based on the value used by Chen et $\mathrm{al}^{10}$ who used similar IEMs for a similar application. $5 \mathrm{~L}$ of three different streams were processed through the ED unit in a batch mode: (1) UF permeate; (2) NF retentate; (3) Dia-NF retentate (see Table 1). The demineralisation process was terminated when the final diluate conductivity was $0.7 \mathrm{mS} / \mathrm{cm}$ for UF permeate and $2.6 \mathrm{mS} / \mathrm{cm}$ for the NF and Dia-NF retentate, which corresponds to a $90 \%$ reduction in feed conductivity. It is important to note that the NF and Dia-NF retentate were at least 3.5 times more concentrated than the UF permeate, therefore the selected final conductivity of these solutions were 3.5 times higher than the UF permeate. 
The flowrates of the diluate, concentrate and electrolyte solution were set at $200 \mathrm{~L} / \mathrm{hr}$ as recommended by the manufacturer to minimize concentration polarization effects in the ED unit. The flowrates of all streams were increased to $300 \mathrm{~L} / \mathrm{hr}$ during the cleaning steps, as this is a common practice used in industry. ${ }^{15}$ During the ED experiments the temperature of all streams was maintained at $35 \pm 4{ }^{\circ} \mathrm{C}$, by circulating cooling water around all three tanks. At the end of the trials, the unit was disassembled and the membranes were stored in purified water (>8.6 M $\Omega \mathrm{cm}$; Merck Millipore KGaA, Germany) before membrane characterization was carried out.

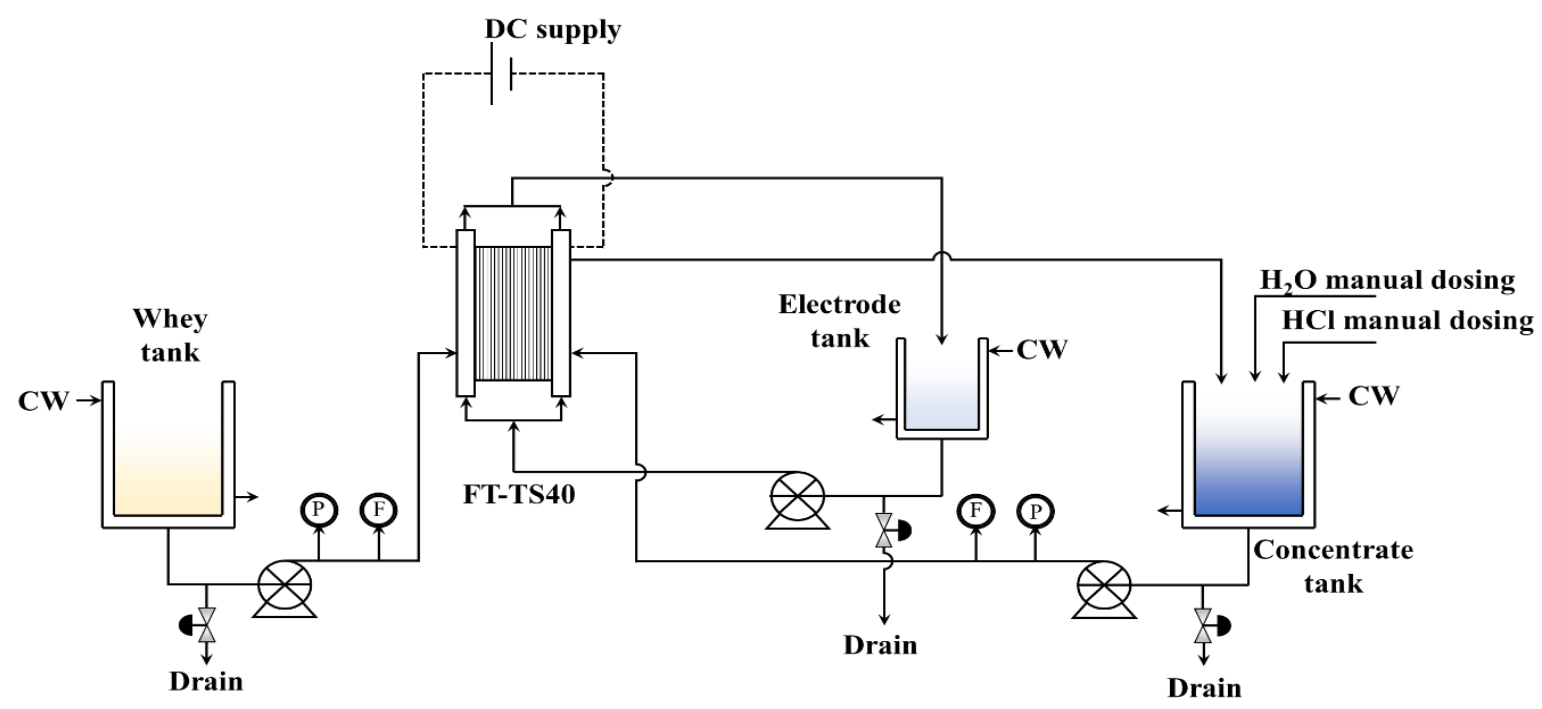

Figure 2. A schematic diagram of the electrodialysis pilot plant where $\mathrm{CW}=$ cooling water; $\mathrm{P}$ $=$ pressure gauge $; \mathrm{DC}=$ direct current; and $\mathrm{F}=$ flowmeter.

\section{Evaporator and dryer}

The lactose rich stream from the NF+ED process was remixed with the protein-rich retentate stream collected from the UF process to create a solution with $8 \%$ protein content. This solution and the original raw acid whey were then processed by evaporation and drying at CSIRO Food Innovation Centre (Werribee, Australia) to produce powdered products. A two-effect falling 
film evaporator operating under vacuum was used with the first and second effects operating at $76^{\circ} \mathrm{C}$ and $62^{\circ} \mathrm{C}$, respectively. The combined UF retentate and $\mathrm{NF}+\mathrm{ED}$ solution was concentrated to $55 \%$ total solid (TS), while the raw acid whey was concentrated to $45 \%$ TS. Rotary dryers supplied with hot air at $180^{\circ} \mathrm{C}$ were used to produce the powders, with outlet air temperature set at $80^{\circ} \mathrm{C}$.

\section{Analysis}

The $\mathrm{pH}$ and conductivity of the ED concentrate tank were measured continuously using a $\mathrm{pH}$ and conductivity meter (Mettler-Toledo, Greifensee, Switzerland). The conductivity of the concentrate tank was always maintained below $15 \mathrm{mS} / \mathrm{cm}$ by adding a total of $2.5 \mathrm{~L}$ of tap water and draining a total of $2.5 \mathrm{~L}$ of the concentrate tank content using the drain valve on the tank (see Figure 2). The adjustment of concentrate conductivity in this manner is a common practice ${ }^{6}$ which can reduce the possibility of mineral scaling. ${ }^{11}$ In a similar manner, the $\mathrm{pH}$ of the concentrate was maintained below 3 to reduce the possibility of mineral scaling and to increase lactic acid transfer. ${ }^{11,16}$ The conductivity and $\mathrm{pH}$ of the diluate stream were measured using a second conductivity meter (Crison Instruments, Greifensee, Switzerland) and pH meter.

The percentage change in conductivity, also known as the demineralization rate (DR), was calculated based on the conductivity of the diluate tank according to Eq. (1). ${ }^{17}$

$$
D R(\%)=\frac{\chi_{\text {initial }}-\chi_{\text {final }}}{\chi_{\text {inital }}} \times 100=\left(1-\frac{\chi_{\text {final }}}{\chi_{\text {initial }}}\right) \times 100
$$

Eq. (1)

where $\chi$ is the conductivity of the diluate solution $(\mu \mathrm{S} / \mathrm{cm})$.

The specific energy consumed during ED was calculated according to Eq. (2), while the specific energy consumption of the NF and Dia-NF process was calculated using Eq. (3). 
$E_{E D}(k W h /$ tonne of feed $)=\frac{V_{\text {cell }} \int I d t}{\text { mass of diluate }}$

Eq. (2)

Where $V_{\text {cell }}$ is the mean stack potential (V), $t$ is the time (hour), $I$ is the current (A).

$E_{N F / D i a-N F}(k W h /$ tonne of feed $)=\frac{P_{e} \cdot t}{\text { mass of feed }}$

Eq.

Where $P_{e}$ is the electric power determined using pump curves $(\mathrm{kW})$.

To calculate the annual energy consumption of NF, Dia-NF and ED, the annual tonnes of feed supplied to each process was multiplied by the energy required to treat one tonne of this feed (calculated using Eq. (2) and (3)). Specifically, for the basis of 200 tonnes of acid whey per year and considering the concentration factors of the UF and NF/Dia-NF processes, 160 tonnes of UF permeate and 40 tonnes of NF and Dia-NF are processed annually.

In the ED process, the current efficiency refers to the ratio between the number of ions transferred and the total charge supplied (Eq. (4)). This parameter is important to assess process efficiency at the selected operating conditions. The current efficiency was calculated using the concentration of the four main cations found in acid whey (sodium, potassium, calcium, magnesium) due to the complexity of the anions present in acid whey. ${ }^{10}$

$\eta(\%)=\frac{F \cdot \mathrm{V}_{D}\left(\sum z_{j} \cdot C_{D j, \text { initial }}-\sum z_{j} \cdot C_{D j, \text { final }}\right)}{n \int I d t} \times 100 \%$

Where $F$ is the Faraday constant $(96,486 \mathrm{C} / \mathrm{mol}), n$ is the number of cell pairs, $V_{D}$ is the diluate tank volume (L), $z_{j}$ is the valance of ion $\mathrm{j}$, and $C_{D j}$ is the concentration of ion $\mathrm{j}$ in the diluate $\operatorname{tank}(\mathrm{mol} / \mathrm{L})$. 
Samples were taken every 10-15 min from the ED diluate tank and analysed using inductively coupled plasma optical emission spectroscopy (ICP-OES 720ES, Varian, USA) to measure the concentration of calcium $(\mathrm{Ca})$, sodium $(\mathrm{Na})$, magnesium $(\mathrm{Mg})$, potassium $(\mathrm{K})$ and phosphorus (P). High-performance liquid chromatography (HPLC, Shimadzu, Japan) was used to measure lactic acid and lactose concentrations in the collected samples. Ion chromatography (ICDionex, ICS-1000, Thermo Fisher Scientific Australia Pty. Ltd., Australia) was used to measure the concentration of chloride $(\mathrm{Cl})$. All samples were filtered and diluted according to the equipment detection limits. Information on the operating parameters of the ICP-OES, HPLC and IC can be found elsewhere. ${ }^{10,18}$ The ion concentrations were used to calculate the percentage ion removal during the NF, Dia-NF and ED processes according to Eq. (5).

Ion Removal $(\%)=\frac{\left(C_{j, \text { UFpermeate }} V_{U F \text { permeate }}-C_{j, \text { NFout }} \cdot V_{N F o u t}\right)+\left(C_{j, \text { Din }}-C_{j, \text { Dout }}\right) \cdot V_{D}}{C_{j, \text { UFpermeate }} \cdot V_{U F p e r m e a t e}} \times 100$ Eq. (5)

Where $\mathrm{C}_{\mathrm{j}}$ and $\mathrm{V}$ are the concentration of ion $\mathrm{j}$ and volume of the relevant streams moving in and out of the processes i.e. UF permeate, dia-NF or NF retentate and ED diluate. The thickness of the IEMs was measured using a Digimatic Micrometer (Mitutoyo, Japan). The membranes were first wiped dry using Kimwipe tissues (Kimtech, Australia). Nine random measurements were taken for selected membranes and the average thickness values are reported. Fourier Transform Infrared (FT-IR, PerkinElmer Spectrum 100, North America) was used to compare the chemical structure and the surface groups of the used and fresh IEMs. Eight scans for wavelengths between $800-2000 \mathrm{~nm}$ were completed per sample and the averaged value is presented here. Membrane surface images were captured using a Scanning Electron Microscope (SEM, FEI Quanta 200 ESEM FEG, Thermo Fisher Scientific, USA). Information on membrane preparation for FTIR and SEM can be found elsewhere. ${ }^{19,20}$ Images of the dried powder were taken using an optical microscope (Prism Optical, SciTech, Australia). 
The UF, NF and Dia-NF experiments were repeated at least 5 times while the ED experiments were repeated at least twice. The data presented in this study is the average value \pm one standard deviation of these results.

\section{Results and discussion}

\section{Demineralization and deacidification of acid whey}

The concentration of lactic acid in the UF permeate was similar to the raw acid whey (Table 1), as expected due to the difference between the UF pore size and the lactate anion. However, a significant difference in the lactic acid concentration was noticed between the NF and DiaNF retentates. The Dia-NF process assisted in removing more lactic acid and monovalent cations. As shown in Figure 3, 71\% and 48\% of the lactic acid and total cations were removed in the Dia-NF process, while only $42 \%$ and $36 \%$ were removed using the NF process, respectively. Nevertheless, the degree of lactic acid removal in both processes is higher than the values reported by both Chandrapala \& Chen et al. ${ }^{7}$ and Chandrapala et al.. ${ }^{9}$ This may have related to the use of spiral wound membranes rather than flat sheet laboratory coupons, which could have led to differences in bulk concentration and in concentration polarisation along the module length. Furthermore, the combination of Dia-NF and ED resulted in the greatest removal of lactic acid (Figure 3). The lactic acid to lactose ratio (Table 2) in all three products of the ED process was below $0.04 \mathrm{~g} \mathrm{LA} / \mathrm{g}$ Lactose, indicating that the solution should not produce a sticky powder. ${ }^{2}$ 


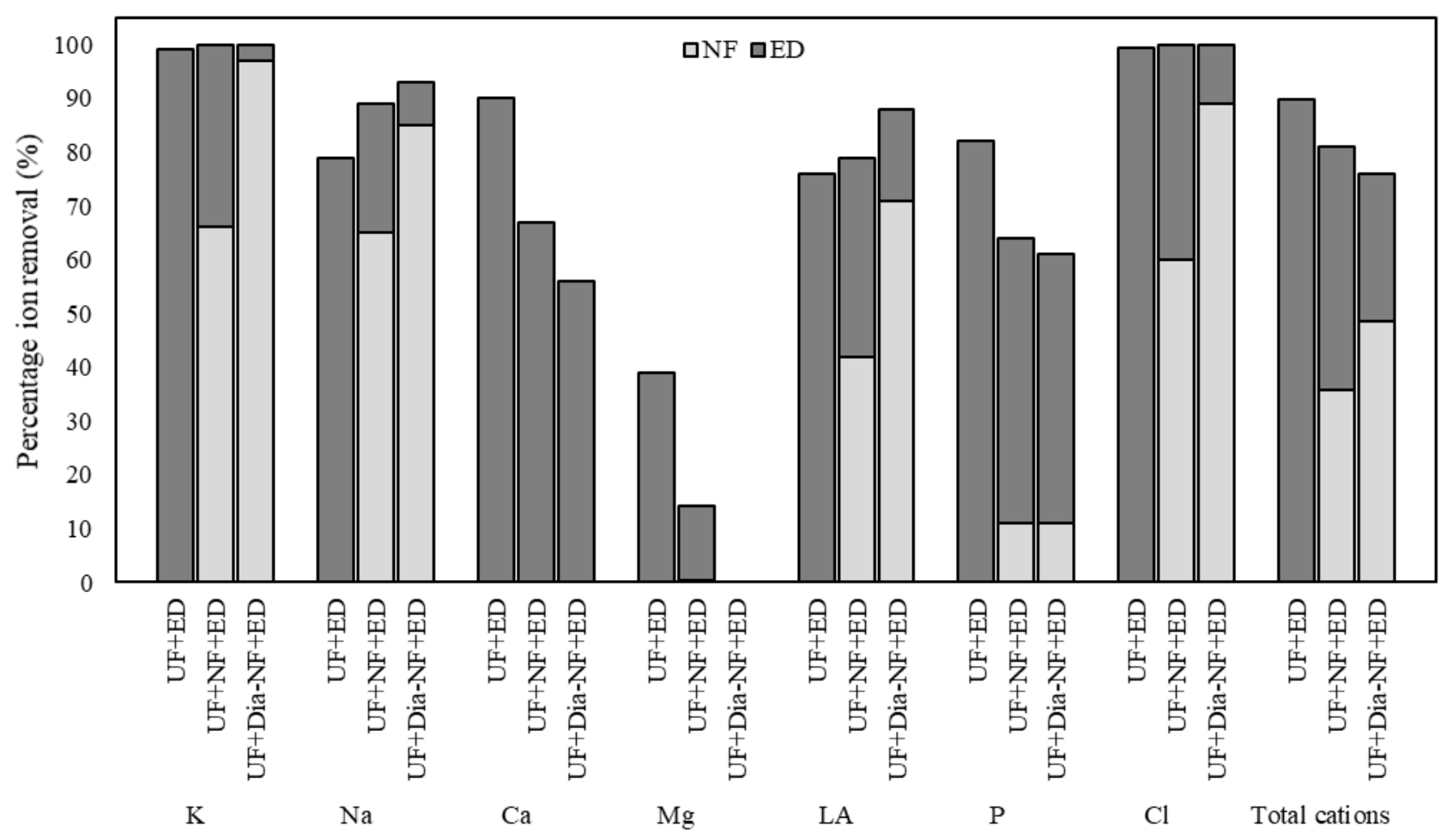

Figure 3. Percentage removal of different components of acid whey. The total cations were calculated based on both monovalent $(\mathrm{K}$ and $\mathrm{Na}$ ) and divalent $(\mathrm{Ca}, \mathrm{Mg})$ cations. 
Table 2. Final diluate compositions following electrodialysis.

\begin{tabular}{lllll}
\hline Component & Unit & $\begin{array}{l}\text { Demineralized } \\
\text { and deacidified }\end{array}$ & $\begin{array}{l}\text { Demineralized, deacidified and } \\
\text { concentrated (CF=3.5-4) })^{(\mathrm{a})}\end{array}$ \\
\cline { 5 - 5 } & & UF+ED & UF+NF+ED & UF +Dia-NF+ED \\
\hline $\mathrm{pH}$ & - & $3.9 \pm 0.1$ & $3.8 \pm 0.1$ & $4.2 \pm 0.1$ \\
$\mathrm{Conductivity}$ & $\mathrm{mS} / \mathrm{cm}$ & $0.71 \pm 0.03$ & $2.63 \pm 0.03$ & $2.6 \pm 0.05$ \\
$\mathrm{~K}$ & $\mathrm{mg} / 100 \mathrm{~mL}$ & $0.9 \pm 0.7$ & $1.9 \pm 0.4$ & $1.2 \pm 2$ \\
$\mathrm{Na}$ & $\mathrm{mg} / 100 \mathrm{~mL}$ & $9 \pm 4$ & $16 \pm 2$ & $10 \pm 2$ \\
$\mathrm{Ca}$ & $\mathrm{mg} / 100 \mathrm{~mL}$ & $12 \pm 0.5$ & $132 \pm 7$ & $177 \pm 5$ \\
$\mathrm{Mg}$ & $\mathrm{mg} / 100 \mathrm{~mL}$ & $7 \pm 0.3$ & $35 \pm 2$ & $45 \pm 3$ \\
$\mathrm{P}$ & $\mathrm{mg} / 100 \mathrm{~mL}$ & $11 \pm 1$ & $70 \pm 6$ & $92 \pm 5$ \\
$\mathrm{Cl}$ & $\mathrm{mg} / 100 \mathrm{~mL}$ & $\mathrm{Not}$ measured & $1.2 \pm 0.7$ & $0.5 \pm 0.2$ \\
Lactate & $\mathrm{g} / \mathrm{L}$ & $1.4 \pm 0.1$ & $4.3 \pm 1$ & $2.6 \pm 0.5$ \\
Lactose & $\mathrm{g} / \mathrm{L}$ & $36 \pm 3$ & $134 \pm 5$ & $150 \pm 3$ \\
Lactic acid/ lactose ratio & $\mathrm{g} / \mathrm{g}$ & $0.038 \pm 0.003$ & $0.032 \pm 0.002$ & $0.017 \pm 0.002$ \\
ED Current efficiency & $\%$ & $82 \pm 1$ & $81 \pm 2$ & $103 \pm 1$ \\
\hline
\end{tabular}

${ }^{\mathrm{a}} \mathrm{CF}=$ concentration factor

The percentage change in conductivity for all three different feeds processed through the ED unit is shown in Figure 4. The Dia-NF retentate required the shortest time to obtain the target final conductivity $(0.7 \mathrm{mS} / \mathrm{cm}$ (UF permeate) and $2.6 \mathrm{mS} / \mathrm{cm}$ (NF and Dia-NF retentate)), reflecting the lower initial conductivity. Although the percentage removal of monovalent ions in both $\mathrm{UF}+\mathrm{NF}+\mathrm{ED}$ and UF+Dia-NF+ED was above $90 \%$, the percentage removal of divalent ions was lower due to their larger hydraulic diameter which results in lower diffusion/migration rates in both pressure and electrically driven membrane processes. ${ }^{16,21}$ Interestingly, no $\mathrm{Mg}$ was removed within experimental error when Dia-NF was used. Furthermore, the total removal of calcium was lower for the UF+Dia-NF+ED process compared to the two other processes. This can be a result of the short processing time during the ED step for the UF+Dia-NF+ED process thus not allowing enough time for $\mathrm{Ca}$ and $\mathrm{Mg}$ migration. Furthermore, since the $\mathrm{NF}$ and Dia-NF retentates were 3.5-4 times higher in concentration compared to UF permeate, 
concentration polarization on the IEM surfaces can result in lower divalent ion removal. Nevertheless, retaining greater amounts of $\mathrm{Ca}$ and $\mathrm{Mg}$ in the diluate stream has nutritional benefits in comparison to $\mathrm{Na} .^{22}$

The $\mathrm{pH}$ of the diluate dropped during the ED process (Figure 4); such a behaviour was also noticed by Dufton et al. ${ }^{23}$ This is predicted to be the result of several phenomena. Under the application of an electrical current, the lactate ions will migrate to the concentrate compartment and pair with the available protons (the concentrate $\mathrm{pH}$ is always maintained below 3 ). The migration of lactate reduces the lactate concentration in the diluate stream, favouring the dissociation reaction of lactic acid to generate more lactate and protons and thus reducing the $\mathrm{pH}$ of this stream. Further, since the concentrate compartment was always maintained at a $\mathrm{pH}$ below 3 by the addition of $\mathrm{HCl}$, the difference in proton concentration between concentrate and diluate can also result in Fickian diffusion of protons from the concentrate stream to the diluate stream. This hypothesis can be supported by the fact that the concentrate $\mathrm{pH}$ always increased during experiments indicating loss of $\mathrm{H}^{+}$. Finally, the shift in diluate $\mathrm{pH}$ could also be a result of water splitting during the experiments. While the applied current density was below the estimated limiting current density at the commencement of each experiment, the value of the limiting current density is expected to fall during the experiment as demineralisation takes place. 

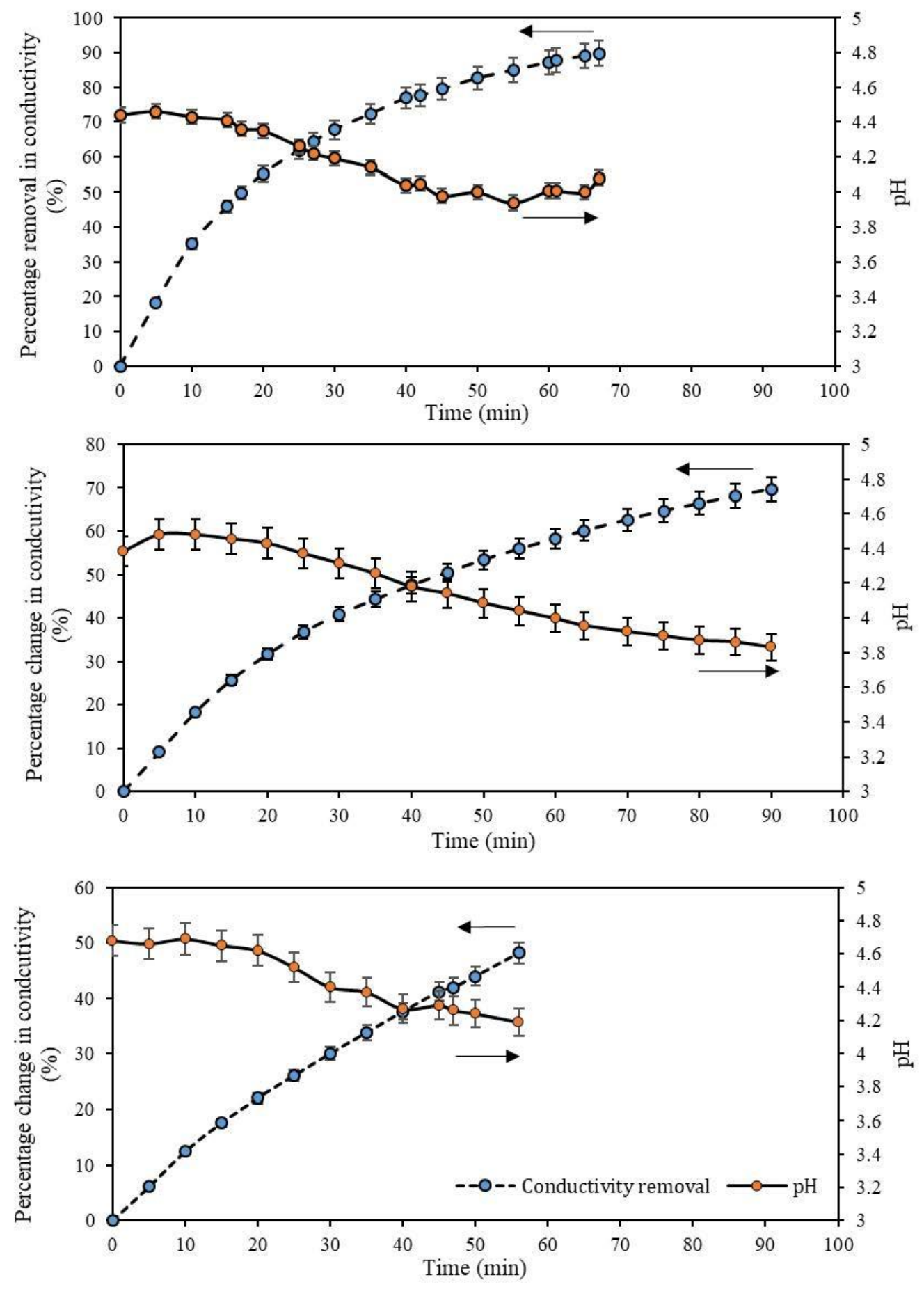

Figure 4. Change in diluate conductivity and $\mathrm{pH}$ as a function of time during electrodialysis of (a) UF permeate, (b) NF retentate, and (c) Dia-NF retentate. 
The current efficiency in the ED processes using UF permeate and NF retentate were around $81 \%$ (See Table 2), comparable to the values reported by Chen et al.. ${ }^{10}$ This indicates a good system performance with little water splitting. However, a current efficiency of $103 \pm 1 \%$ was obtained for the Dia-NF retentate. Values larger than $100 \%$ have been reported by several researchers such as Alhéritière et al. ${ }^{24}$ and were explained to be a result of either Fickian diffusion or convective transport through the membranes.

\section{Energy consumption}

The energy required for the ED step of the UF permeate $(7.5 \mathrm{kWh} /$ tonne of feed) was lower than the energy required for the NF retentate $(14.5 \mathrm{kWh} /$ tonne of feed), see Figure 5 (a). The higher feed concentrations result in higher energy consumption due to the greater number of ions that must be moved per tonne of feed. ${ }^{25}$ Diafiltration reduces the ionic concentrations, thus reducing this energy demand. Thus, the energy consumption for ED of this stream was lower $(7.8 \mathrm{kWh} /$ tonne of feed).

Figure 5 (b) shows the energy costs for the three processes, based on the processing of 200 tonnes per annum of acid whey. The energy cost of the UF process is not included as this step is common between all three proposed processes. The energy consumption of the NF step is calculated to be $10 \mathrm{kWh} /$ tonne of feed processed through the unit (Eq. (3)) which equates to $1600 \mathrm{kWh} / \mathrm{year}$. This energy cost doubles to $3200 \mathrm{kWh} / \mathrm{year}$ for the Dia-NF, as double the volume is processed. Similarly, the annual energy consumed for the UF permeate through the ED unit is higher than the NF and Dia-NF retentate due to its greater volume, while this energy demand is smallest for Dia-NF due to the small volume and low ionic concentration. For the process involving UF and ED only, the final product is 3.5 to 4 times more dilute than the NF and Dia-NF retentate, so there is an additional energy cost for concentrating this product stream prior to evaporation. The expected cost for this concentration step is also shown in Figure 5(b) 
(calculated using Eq. (3), assuming that the same NF unit is used for this purpose). In addition to the lower annual energy demand of the NF and Dia-NF retentate, the area of the IEMs required to achieve the desired levels of demineralization will be significantly smaller for these processes compared to the UF permeate. Considering that the price of ED membranes is significantly higher than that of pressure driven membranes, this will lead to lower capital costs. When looking at the total energy consumed, NF retentate has the lowest total energy consumption comparing to the other two types of feed (Figure 5 (b)). Dia-NF is advised if high levels of lactic acid removal is necessary, however, due to the large volumes of permeate, it may be useful to consider the use of reverse osmosis (RO) to recover high purity water that can be re-used in the Dia-NF process. 
(a)

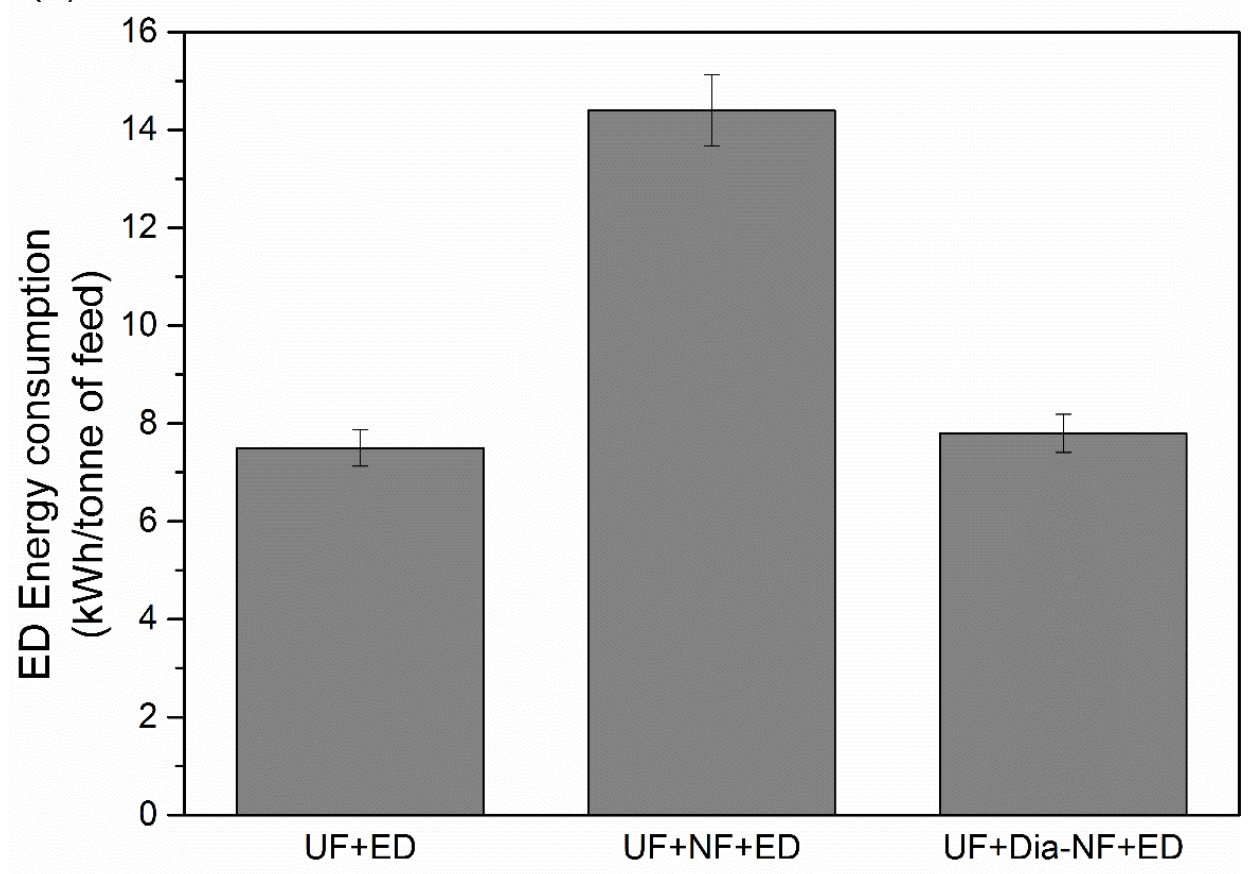

(b)

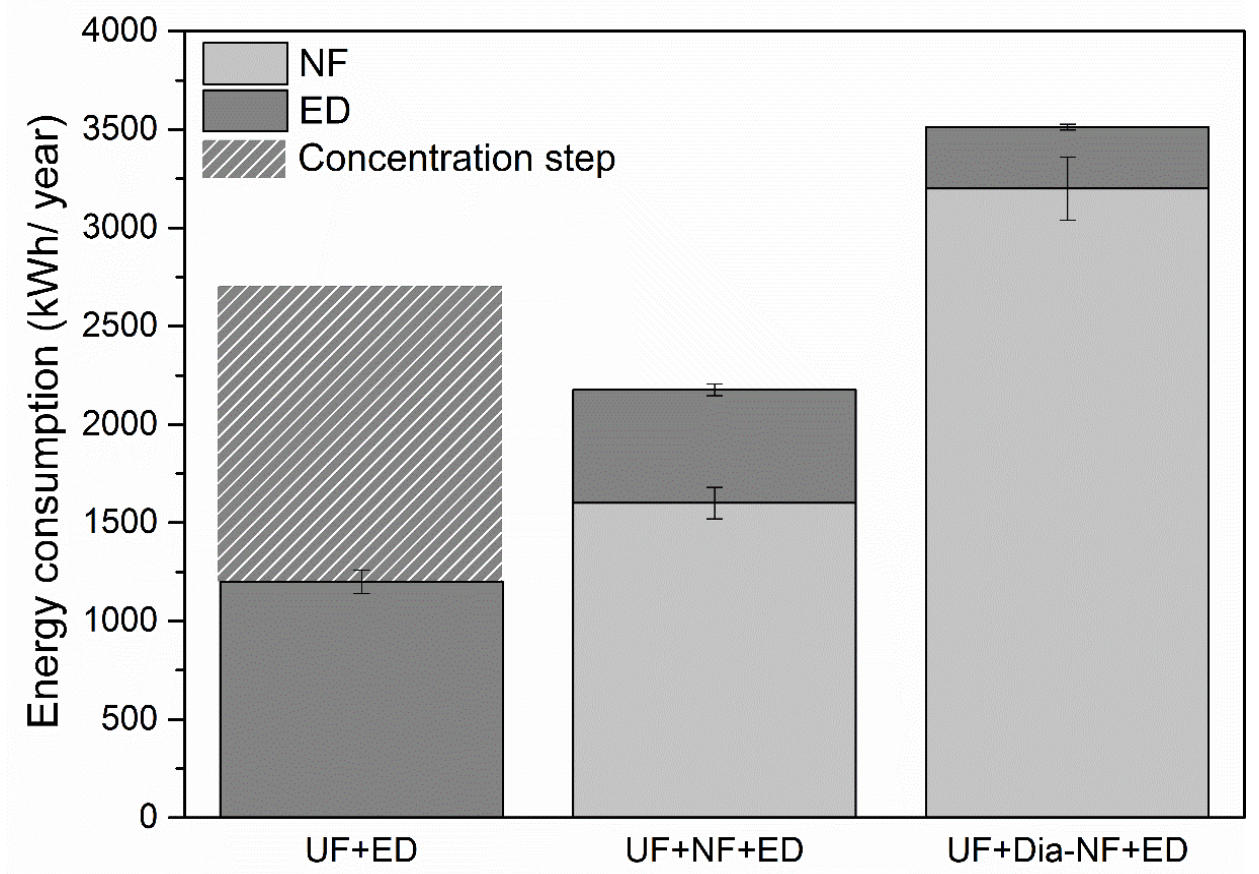

Figure 5. Energy consumption of the three proposed processes. (a) Energy consumption of the ED process per tonne of feed. (b) Annual energy consumption base on 200 tonnes of acid whey per year. 


\section{Ion-exchange membrane analysis}

No visual fouling was observed on the surface of the membranes when the ED unit was disassembled at the end of the trials. This was somewhat expected as the protein content of the feed solutions was low and the concentrate solution was maintained at a $\mathrm{pH}$ below 3 thus eliminating mineral scaling. ${ }^{11}$

The average thicknesses of the used CMB membranes were similar to the fresh membrane (Figure 6 (a)), expect for the CMB membrane facing the cathode compartment. When FTIR analysis was performed on these membranes, it was found that the absorbance spectrum for the cathode $\mathrm{CMB}$ was also different when compared to the other used membranes and the fresh membrane (Figure 7 (a)). Furthermore, SEM imagines (Figure 8 (c \& d)) showed cracks and deformation on the surface of the cathode CMB. This suggests that damaging electrode reactions may have occurred. An alternate electrode material to the stainless steel used here may alleviate this issue.

The AHA membranes neighbouring the anode and cathode electrode were slightly thicker than the fresh membranes and the other AHA membranes after use (Figure 6 (b)). Further, all used AHA membranes were darker in color than the fresh materials (Figure 7 (b)). AHA membranes are known to incorporate charged amine and/or amide groups, such as $-\mathrm{NH}_{3}^{+},-\mathrm{NRH}_{2}^{+}$, $N R_{2} H^{+}$, and $-N R_{3}^{+}$. Maillard reactions may take place between these fixed charges and the lactose present in acid whey, producing $\mathrm{N}$-containing polymers known as melanoidins, which are brown in color. ${ }^{26}$ While Maillard reactions are usually favoured only above $140^{\circ} \mathrm{C}$, Choi and Moon ${ }^{27}$ suggest that the temperature of the IEMs may be higher than the bulk solutions when subjected to electrical fields and this may have accelerated their formation. Maillard reactions can be observed by the formation of new peaks in the FTIR spectrum between 1630 and $1650 \mathrm{~cm}^{-1}(\mathrm{C}=\mathrm{N} \text { stretching })^{28}$ as is indeed observed for the used membranes in Figure 7 
(b). However, the increased absorbance in this region could also occur through adsorption of proteins within the membrane, which would increase the Amide I (1600 -1700 $\left.\mathrm{cm}^{-1}\right)$ and Amide II peaks $\left(1500-1600 \mathrm{~cm}^{-1}\right)$.

Choi and Moon ${ }^{27}$ and Zabolotskii et al. ${ }^{29}$ indicate that under the application of strong electrical fields, the quaternary ammonium groups in anion exchange membranes can react with $\mathrm{OH}^{-}$ions produced as a result of water splitting to form weakly basic (secondary and ternary) amino groups. This can be observed by the introduction of a new peak in the region $1020-1200 \mathrm{~cm}^{-1}$ as is indeed observed in Figure 7 (b). Regardless of these physical and chemical changes, SEM images (Figure 8 (f)) did not show any structural damage. 

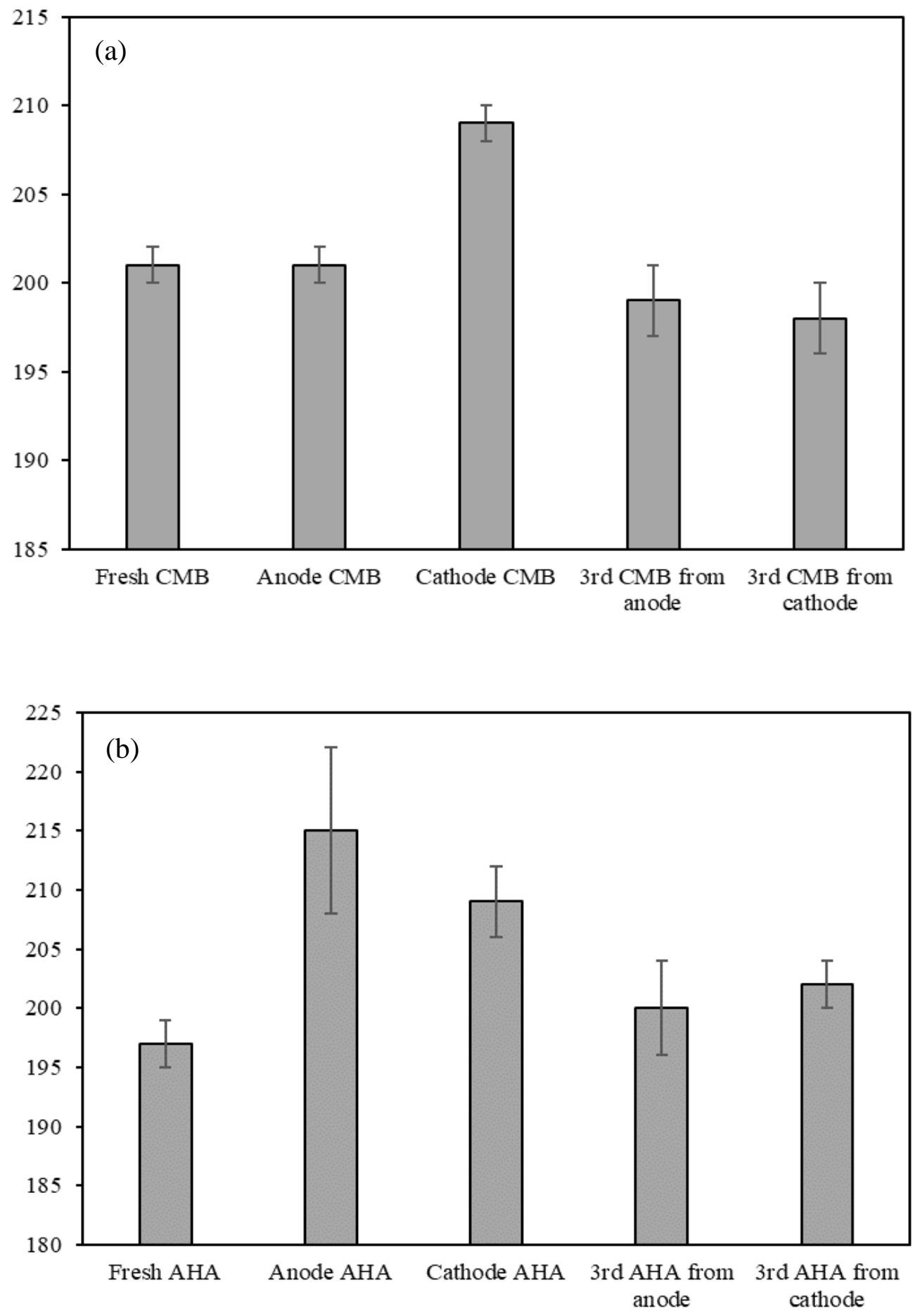

Figure 6. Average membrane thickness for randomly selected: (a) CMB membranes, and (b) AHA membranes. 
(a)

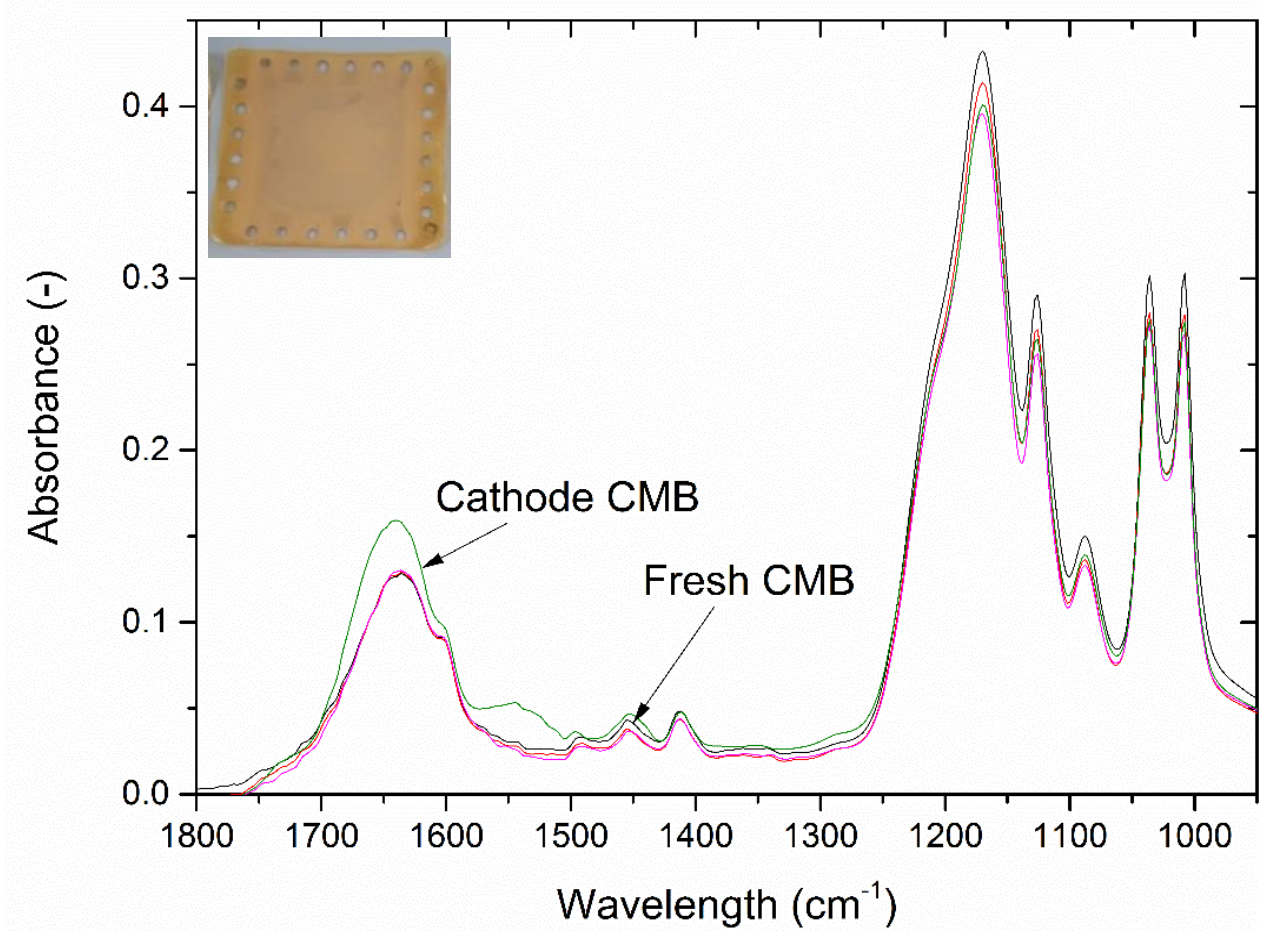

(b)

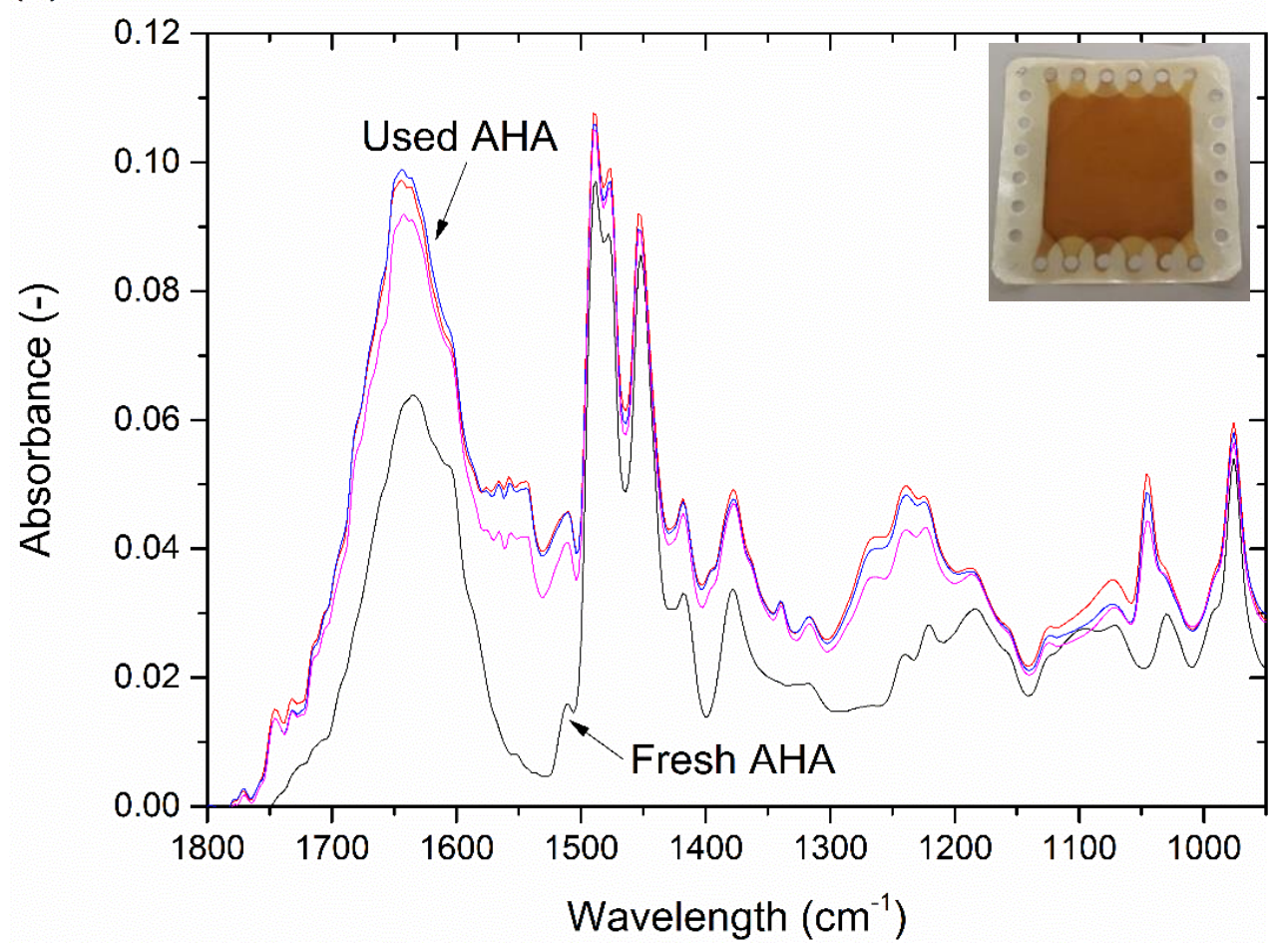

Figure 7. FTIR analysis for (a) CMB and (b) AHA membranes used in the electrodialysis trials. 
(a)

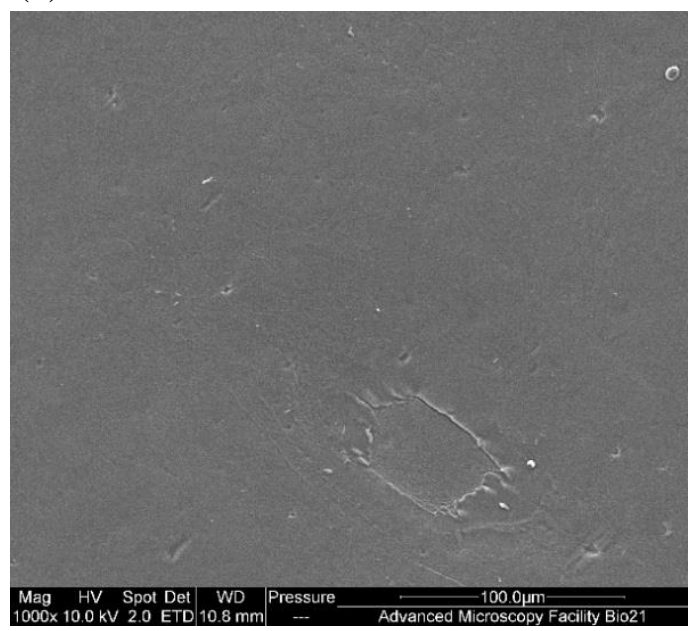

(c)

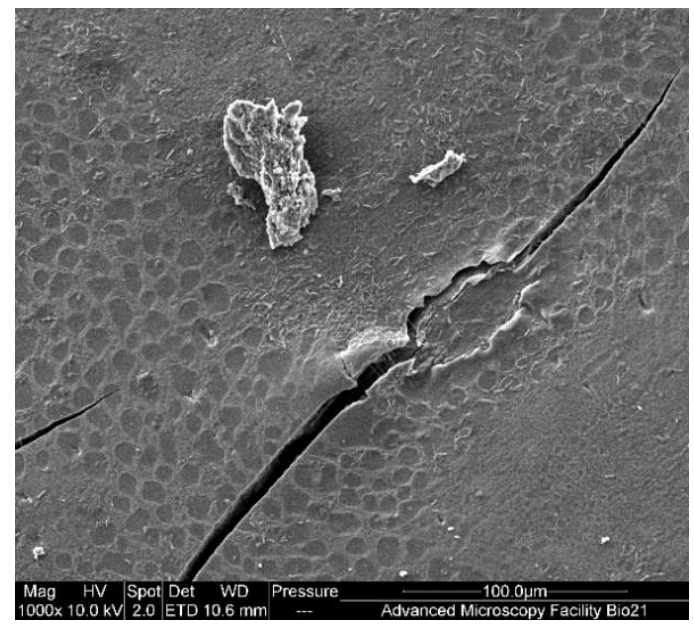

(e)

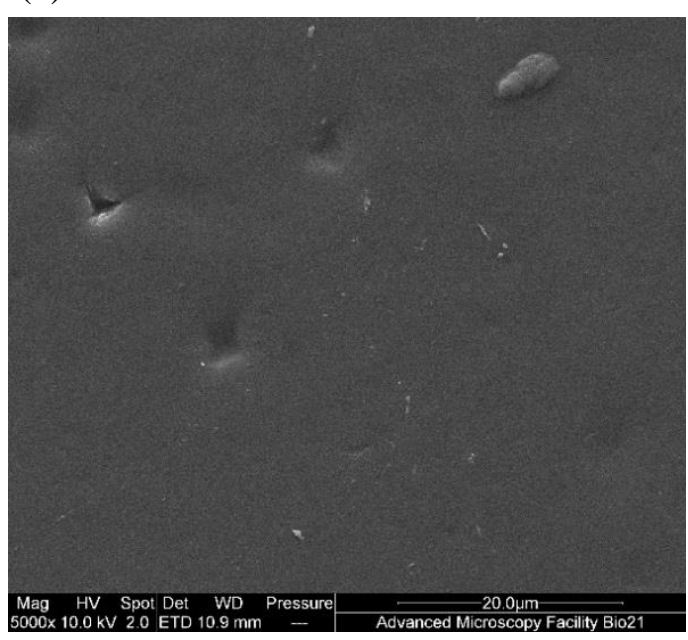

(b)

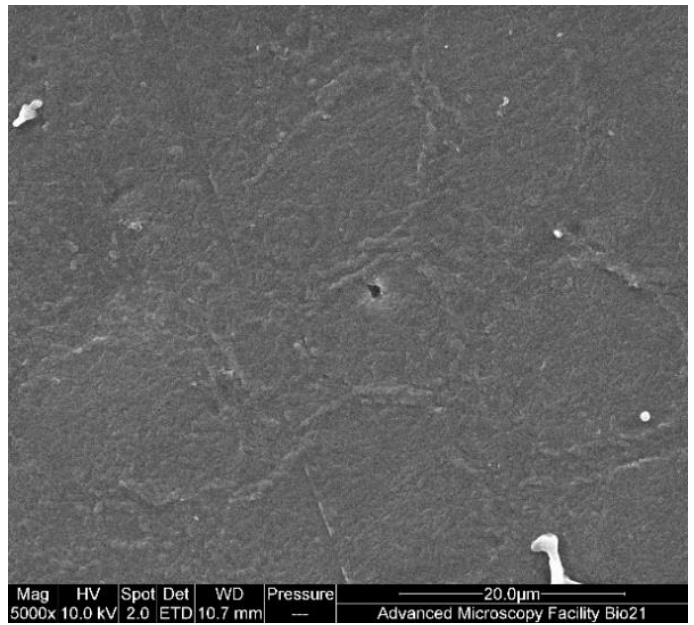

(d)

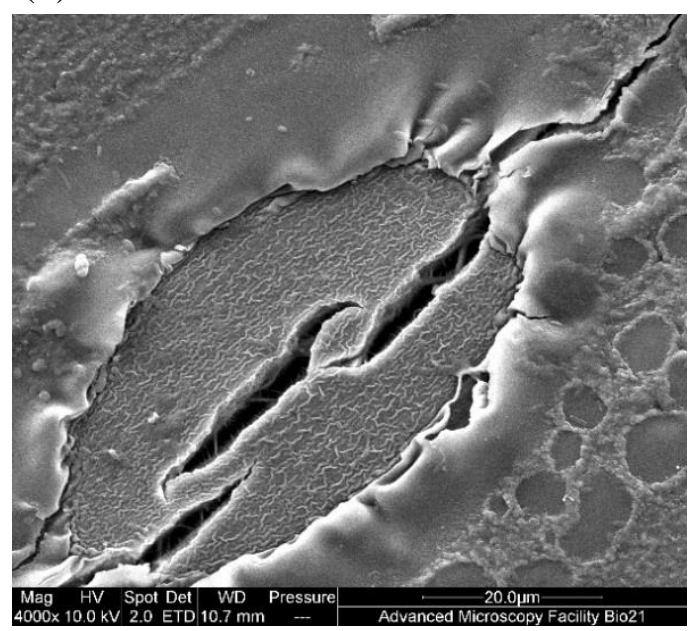

(f)

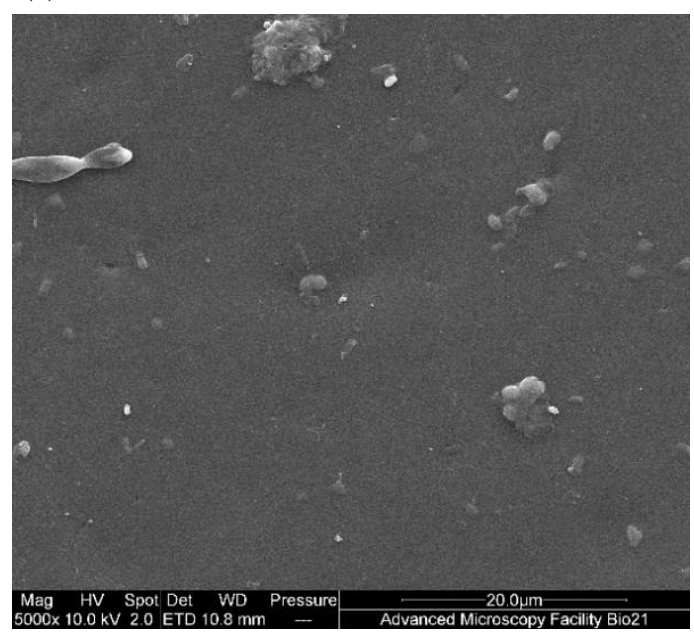

Figure 8. SEM images of the membrane surface for (a) fresh CBM, (b) used CMB, (c \& d) CMB facing cathode, (e) fresh AHA, and (f) used AHA. 


\section{Acid whey powder characterization}

When the raw acid whey was dried, it stuck to the surface of the dryer (Figure 9 (b)) as anticipated due to the low glass transition temperature of the lactose causing an amorphous crystal phase to form (Figure 10 (b)). The high levels of lactic acid and calcium are also known to restrict water mobility and removal ${ }^{1}$ resulting in a powder of high moisture content (Table 3).

The lactose rich stream from NF+ED process was remixed with the rich UF protein retentate to create a solution with $8 \%$ protein content, which is similar to the protein content of the raw acid whey. This solution could readily be dried without the formation of sticky deposits (Figure 9 (a)) and with a lower moisture content (Table 3). Furthermore, the optical microscope photos (Figure 10 (a)) show clear tomahawk-like lactose crystals in the powder produced from NF+ED processes. ${ }^{30}$ The final ash content of the NF+ED powder was three times lower than the raw acid whey, providing a product that could meet specifications for $70 \%$ demineralised powder, referred to as D70.

Table 3. Characteristics of the produced acid whey powders.

\begin{tabular}{llll}
\hline Component & Unit & $\begin{array}{l}\text { Raw acid whey } \\
\text { powder }\end{array}$ & $\begin{array}{l}\text { NF+ED treated } \\
\text { powder }\end{array}$ \\
\hline Moisture content $^{\mathrm{a}}$ & $\%$ & 4 & 2.5 \\
Ash content $^{\mathrm{a}}$ & $\%$ & 12 & 4 \\
Lactic acid $^{\mathrm{a}}$ & $\mathrm{g} / \mathrm{g}$ of powder & Unmeasured & 0.026 \\
\hline
\end{tabular}

${ }^{\mathrm{a}}$ Analysis performed by an external laboratory 
(a)

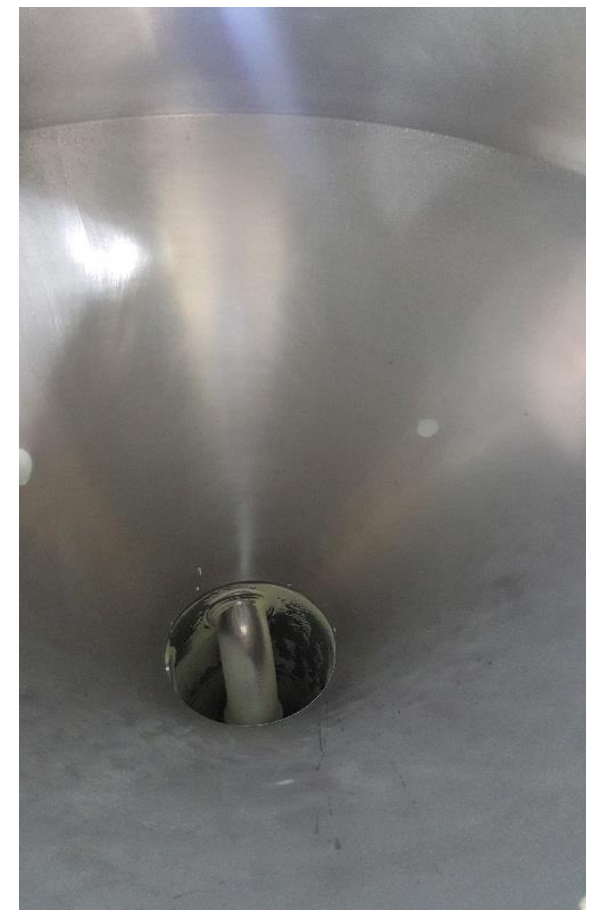

(b)

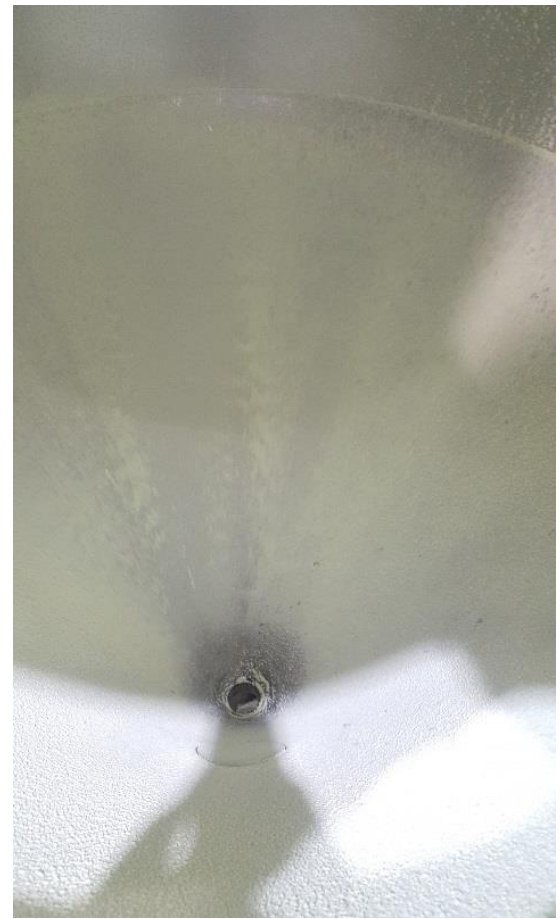

Figure 9. Dryer walls after the production of (a) UF retentate and NF+ED treated powder and (b) raw acid whey powder.

(a)

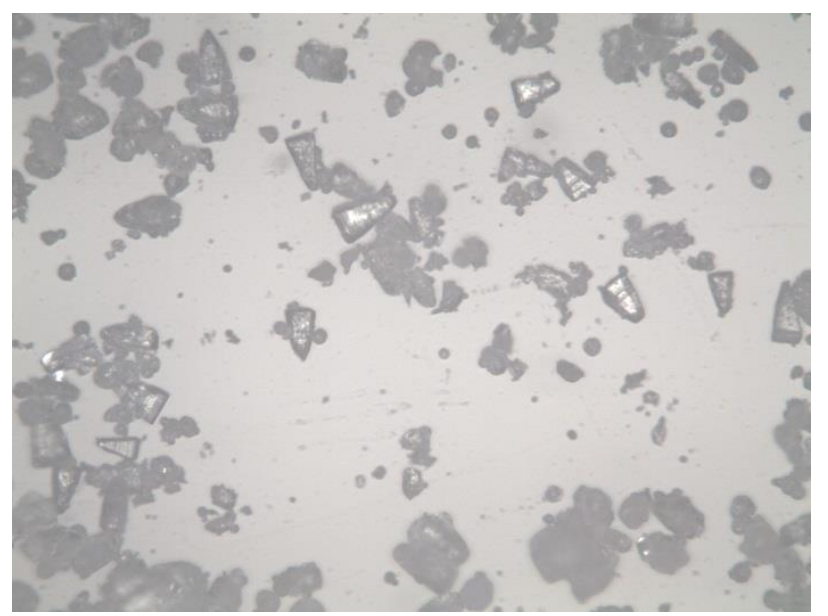

(b)

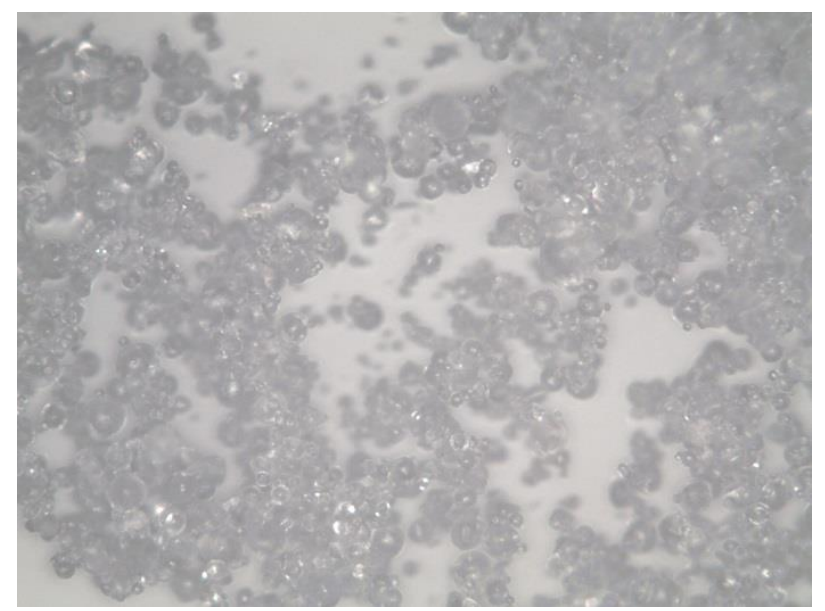

Figure 10. Optical microscope photographs (10x) of (a) UF retentate and NF+ED treated powder and (b) raw acid whey powder. 


\section{Conclusions}

This work has shown the feasibility of combining different membrane processes to produce demineralized whey powders from acid whey, with a special focus on the ED process. The ability to produce consumable products from acid whey not only increases profitability but also reduces waste, leading to a more sustainable dairy industry. A pilot scale ED with a total membrane area of $0.1 \mathrm{~m}^{2}$ was successfully used to reduce the conductivity and lactic acid levels of UF permeate, NF retentate and Dia-NF retentate. The concentrate compartment was maintained at a pH below 3 to control mineral scaling and to increase the lactic acid transfer. While this addition of acid might be considered as unsustainable, the amount used was negligible when compared to the cleaning chemicals that would be required to remove the mineral scaling if this practice had not been used. Similarly, the use of a relatively mild alkaline cleaning step $(\mathrm{pH}$ 10.5) minimised the use of sodium hydroxide, which has a significant embodied energy demand.

The maximum levels of lactic acid removal, $88 \%$, was achieved when Dia-NF was combined with ED. However, the energy cost of the Dia-NF step was double the cost of standard NF. The annual energy consumed during ED was the greatest for the UF permeate due to the large feed volume (1200 kWh/year for an annual volume of 200 tonnes of acid whey). This large feed volume would also result in a significantly larger capital cost, given the high cost of ionexchange membranes, relative to pressure driven membranes. The powder produced from combining the NF+ED lactose rich stream with the rich UF protein retentate was non-sticky, with a moisture content of $2.5 \%$. Although, the combination of UF+NF+ED was successful in reducing the levels of lactic acid and had the lowest annual energy consumption, the best process combination should be selected taking into consideration the capital investment, the operating cost and the facilities available on the manufacturing site. 


\section{Acknowledgments}

This research was supported under Australian Research Council's Industrial Transformation Research Program (ITRP) funding scheme (Project Number IH120100005). The ARC Dairy Innovation Hub is a collaboration between The University of Melbourne, The University of Queensland and Dairy Innovation Australia Ltd. Funding support and provision of acid whey by Bega Cheese Limited is also gratefully acknowledged.

\section{References}

(1) Wijayasinghe, R.; Vasiljevic, T.; Chandrapala, J. Lactose behaviour in the presence of lactic acid and calcium. J. Dairy Res. 2016, 83 (3), 395.

(2) Knipschildt, M.; Andersen, G. In Robinson: Modern Dairy Technology; Springer, 1994.

(3) Buhler, M.; Bohren, H.-U.; Hodel, T. Ultrafiltration process for the recovery of proteins from milk. United States Patent No. 4,018,752, 1977.

(4) Hinkova, A.; Zidova, P.; Pour, V.; Bubnik, Z.; Henke, S.; Salova, A.; Kadlec, P. Potential of Membrane Separation Processes in Cheese Whey Fractionation and Separation. Procedia Eng. 2012, 42, 1425.

(5) Bylund, G. Dairy Processing Handbook; Tetra Pak Processing Systems AB, 2003.

(6) Fidaleo, M.; Moresi, M. Electrodialysis applications in the food industry. Adv. Food \& Nutr. Res. 2006, 51, 265.

(7) Chandrapala, J.; Chen, G. Q.; Kezia, K.; Bowman, E. G.; Vasiljevic, T.; Kentish, S. E. Removal of lactate from acid whey using nanofiltration. J. of Food Eng. 2016, 177, 59.

(8) Bédas, M.; Tanguy, G.; Dolivet, A.; Méjean, S.; Gaucheron, F.; Garric, G.; Senard, G.; Jeantet, R.; Schuck, P. Nanofiltration of lactic acid whey prior to spray drying: Scaling up to a semi-industrial scale. LWT-Food Sci. \& Technol. 2017, 79, 355.

(9) Chandrapala, J.; Duke, M. C.; Gray, S. R.; Weeks, M.; Palmer, M.; Vasiljevic, T. Nanofiltration and nanodiafiltration of acid whey as a function of $\mathrm{pH}$ and temperature. Separ. \& Purificat. Technol. 2016, 160, 18.

(10) Chen, G. Q.; Eschbach, F. I.; Weeks, M.; Gras, S. L.; Kentish, S. E. Removal of lactic acid from acid whey using electrodialysis. Separ. \& Purificat. Technol. 2016, 158, 230.

(11) Talebi, S.; Chen, G. Q.; Freeman, B.; Suarez, F.; Freckleton, A.; Bathurst, K.; Kentish, S. E. Fouling and in-situ cleaning of ion-exchange membranes during the electrodialysis of fresh acid and sweet whey. J. of Food Eng. 2018.

(12) Kelly, J.; Kelly, P. Nanofiltration of whey: Quality, environmental and economic aspects. Int. J. Dairy Technol. 1995, 48 (1), 20. 
(13) Merkel, A.; Ashrafi, A. M.; Ečer, J. Bipolar membrane electrodialysis assisted pH correction of milk whey. J. of Membr. Sci. 2018, 555, 185.

(14) Williams, A. W.; Kline, H. A.; Electrodialysis of acid whey. United States Patent No. 4,227,981, 1980 .

(15) Trägårdh, G. Membrane cleaning. Desalination 1989, 71 (3), 325.

(16) Ayala-Bribiesca, E.; Araya-Farias, M.; Pourcelly, G.; Bazinet, L. Effect of concentrate solution $\mathrm{pH}$ and mineral composition of a whey protein diluate solution on membrane fouling formation during conventional electrodialysis. J. of Membr. Sci.2006, 280 (1), 790.

(17) Cifuentes-Araya, N.; Pourcelly, G.; Bazinet, L. Water splitting proton-barriers for mineral membrane fouling control and their optimization by accurate pulsed modes of electrodialysis. J. of Membr. Sci.2013, 447, 433.

(18) Hassanvand, A.; Chen, G. Q.; Webley, P. A.; Kentish, S. E. A comparison of multicomponent electrosorption in capacitive deionization and membrane capacitive deionization. Water Res. 2018, 131, 100.

(19) Kanehashi, S.; Chen, G. Q.; Scholes, C. A.; Ozcelik, B.; Hua, C.; Ciddor, L.; Southon, P. D.; D’Alessandro, D. M.; Kentish, S. E. Enhancing gas permeability in mixed matrix membranes through tuning the nanoparticle properties. J. of Membr. Sci. 2015, 482, 49.

(20) Tang, C. Y.; Kwon, Y.-N.; Leckie, J. O. Probing the nano-and micro-scales of reverse osmosis membranes-A comprehensive characterization of physiochemical properties of uncoated and coated membranes by XPS, TEM, ATR-FTIR, and streaming potential measurements. J. of Membr. Sci. 2007, 287 (1), 146.

(21) Schaep, J.; Van der Bruggen, B.; Uytterhoeven, S.; Croux, R.; Vandecasteele, C.; Wilms, D.; Van Houtte, E.; Vanlerberghe, F. Removal of hardness from groundwater by nanofiltration. Desalination 1998, 119 (1-3), 295.

(22) Diblíková, L.; Čurda, L.; Kinčl, J. The effect of dry matter and salt addition on cheese whey demineralisation. Int. Dairy J. 2013, 31 (1), 29.

(23) Dufton, G.; Mikhaylin, S.; Gaaloul, S.; Bazinet, L. How electrodialysis configuration influences acid whey deacidification and membrane scaling. J. of Dairy Sci. 2018, 101 (9), 7833.

(24) Alhéritière, C.; Ernst, W. R.; Davis, T. A. Metathesis of magnesium and sodium salt systems by electrodialysis. Desalination 1998, 115 (2), 189.

(25) Lee, H.-J.; Sarfert, F.; Strathmann, H.; Moon, S.-H. Designing of an electrodialysis desalination plant. Desalination 2002, 142 (3), 267.

(26) Rongsirikul, N.; Hongsprabhas, P. Brown pigment formation in heated sugar-protein mixed suspensions containing unmodified and peptically modified whey protein concentrates. J. Food Sci. \& Technol. 2016, 53 (1), 800.

(27) Choi, J.-H.; Moon, S.-H. Structural change of ion-exchange membrane surfaces under high electric fields and its effects on membrane properties. J. Colloid Interf. Sci. 2003, 265 (1), 93.

(28) Monajjemzadeh, F.; Hassanzadeh, D.; Valizadeh, H.; Siahi-Shadbad, M. R.; Mojarrad, J. S.; Robertson, T.; Roberts, M. S. Assessment of feasibility of maillard reaction between baclofen and lactose by liquid chromatography and tandem mass 
spectrometry, application to pre formulation studies. AAPS PharmSciTech 2009, 10 (2), 649.

(29) Zabolotskii, V. I.; Chermit, R. K.; Sharafan, M. V. Mass transfer mechanism and chemical stability of strongly basic anion-exchange membranes under overlimiting current conditions. Russ. J. Electrochem. 2014, 50 (1), 38.

(30) Saito, Z. Lactose crystallization in commercial whey powders and in spray-dried lactose. Food Structure 1988, 7 (1), 9. 
For Table of Contents Use Only.

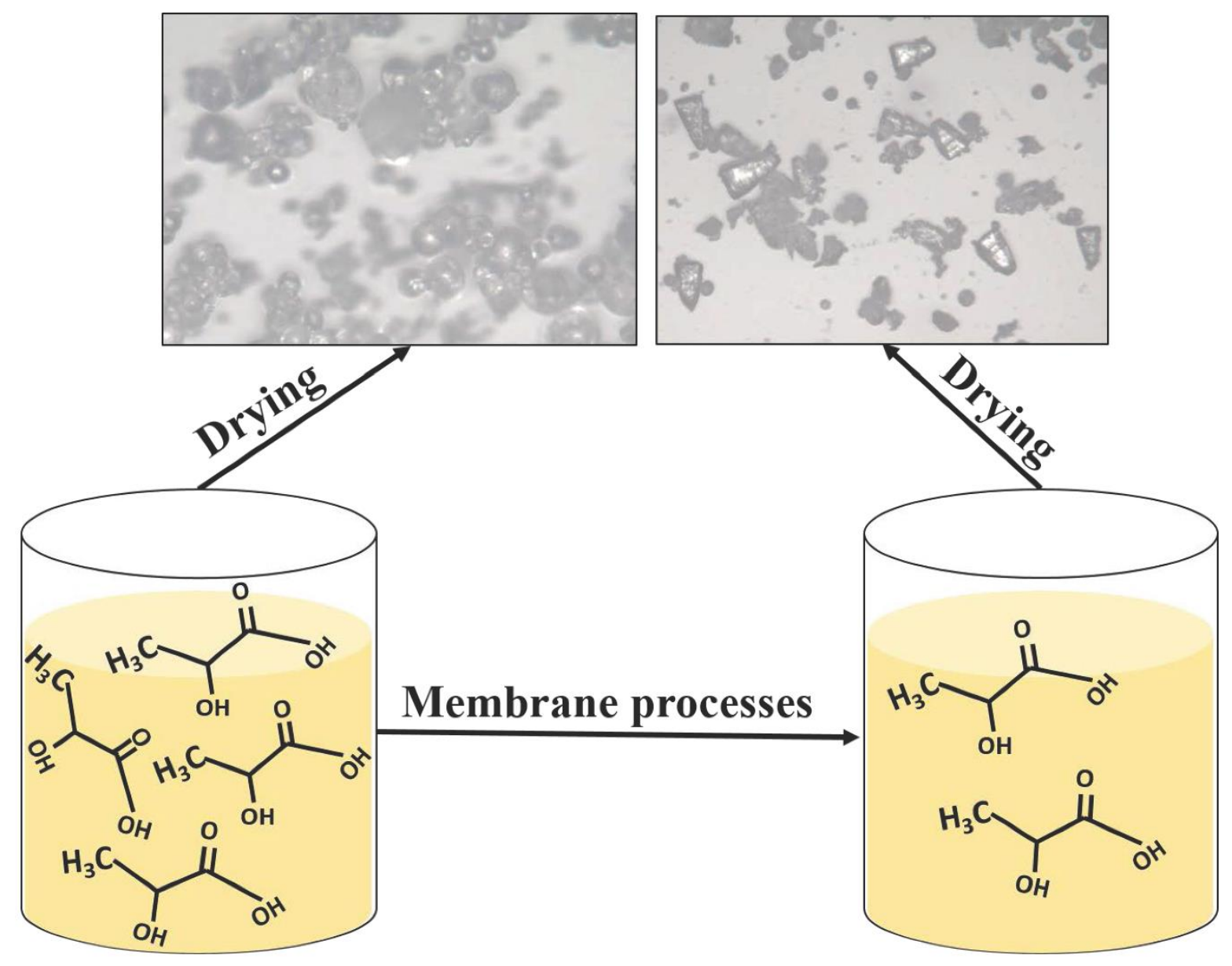

Synopsis:

Removal of lactic acid and minerals from acid whey allows this to be sold as a valuable product rather than becoming an effluent stream. 